\title{
Cycloparaphenylene Double Nanohoop: Structure, Lamellar Packing, and Encapsulation of C60 in the Solid State
}

\author{
Yang, Yong ; Huangfu, Shangxiong ; Sato, Sota ; Juricek, Michal
}

\begin{abstract}
A new member of the cycloparaphenylene double-nanohoop family was synthesized. Its framework features two oval cavities that display different shapes depending on the crystallization conditions. Incorporation of the peropyrene bridge within the nanoring cycles via bay-regions alleviates steric effects and thus allows 1:1 complexation with C60 in the solid state. This nanocarbon adopts a lamellar packing motif, and our results suggest that the structural adjustment of this double nanohoop could enable its use in supramolecular and semiconductive materials.
\end{abstract}

DOI: https://doi.org/10.1021/acs.orglett.1c02950

Posted at the Zurich Open Repository and Archive, University of Zurich

ZORA URL: https://doi.org/10.5167/uzh-215477

Journal Article

Published Version

\section{(c) $(1)$}

The following work is licensed under a Creative Commons: Attribution-NonCommercial-NoDerivatives 4.0 International (CC BY-NC-ND 4.0) License.

Originally published at:

Yang, Yong; Huangfu, Shangxiong; Sato, Sota; Juricek, Michal (2021). Cycloparaphenylene Double Nanohoop: Structure, Lamellar Packing, and Encapsulation of C60 in the Solid State. Organic Letters, 23(20):7943-7948.

DOI: https://doi.org/10.1021/acs.orglett.1c02950 


\title{
Cycloparaphenylene Double Nanohoop: Structure, Lamellar Packing, and Encapsulation of $\mathrm{C}_{60}$ in the Solid State
}

\author{
Yong Yang, Shangxiong Huangfu, Sota Sato, and Michal Jurícek*
}

Cite This: Org. Lett. 2021, 23, 7943-7948

Read Online

ABSTRACT: A new member of the cycloparaphenylene double-nanohoop family was synthesized. Its $\pi$-framework features two oval cavities that display different shapes depending on the crystallization conditions. Incorporation of the peropyrene bridge within the nanoring cycles via bay-regions alleviates steric effects and thus allows 1:1 complexation with $\mathrm{C}_{60}$ in the solid state. This nanocarbon adopts a lamellar packing motif, and our results suggest that the structural adjustment of this double nanohoop could enable its use in supramolecular and semiconductive materials.

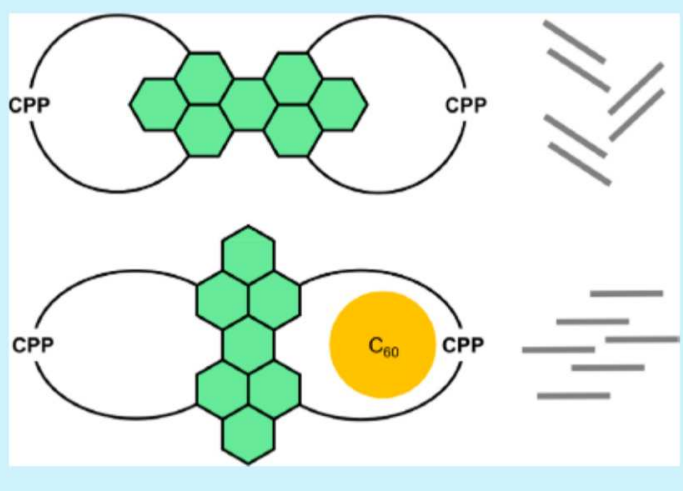

C ycloparaphenylenes (CPPs) are tube-shaped radially $\pi$ conjugated molecular loops composed of distorted paralinked phenylene rings. ${ }^{1}$ These "carbon nanohoops" are investigated as seeds for the size-controlled growth of armchair carbon nanotubes ${ }^{2}$ and materials in the areas of supramolecular chemistry ${ }^{3}$ and materials science. ${ }^{4}$ Since the landmark synthesis of [9]-, [12]-, and [18]CPP in 2008, ${ }^{5}$ a diversity of $[n]$ CPPs and more complex CPP architectures have been developed, including lemniscates, ${ }^{6}$ cylinders, ${ }^{7}$ double nanohoops, ${ }^{8}$ propellers, ${ }^{9}$ cages, ${ }^{10}$ and catenanes, ${ }^{11}$ which has expedited the development of CPP chemistry. The solid-state structures of $[n]$ CPPs were not available until the first single-crystal X-ray diffraction (SC-XRD) characterization of [12]CPP, accomplished in 2011. ${ }^{12}$ Typically, herringbone packing motifs are observed in the solid-state structures of $[n]$ CPPs, ${ }^{3}$ except for [6]CPP, which adopts a columnar packing structure. ${ }^{13}$ Notably, [6]CPP can also display herringbone packing upon adjustment of the crystallization conditions. ${ }^{14}$ Rational manipulation of the packing mode of $[n]$ CPPs is an efficient tactic to implement functionality in the solid state. For example, columnar packing featuring porous channels is favored when $[n]$ CPPs are fluorinated, ${ }^{15}$ carboxylated, ${ }^{16}$ heteroatom-doped, ${ }^{17}$ or reduced to their anionic forms. ${ }^{18}$ Despite the advanced synthetic methodologies that enable size-selective syntheses of $[n]$ CPPs $(n \geq 5),{ }^{19}$ their potential applications as solid-state materials are still rarely explored. $^{20}$

A unique structural feature of CPPs is their radial cavity that enables them to encapsulate fullerenes and small polycyclic aromatic hydrocarbons. ${ }^{3}$ The cavity of [10]CPP was shown to have an ideal diameter for binding $\mathrm{C}_{60}{ }^{21}$ and the solid-state structure of the $1: 1[10] \mathrm{CPP} \supset \mathrm{C}_{60}$ complex revealed a close concave-convex $\pi-\pi$ interaction between the host and the guest. $^{22}$ In addition, it was demonstrated that $[n+5]$ CPPs can selectively encapsulate $[n]$ CPPs to mimic the shortest segment of double-walled carbon nanotubes. ${ }^{23}$ Most recently, a $\pi$ extended [12] CPP analogue was exemplified to accommodate both fullerene $\left(\mathrm{C}_{60}\right.$ or $\left.\mathrm{C}_{70}\right)$ and the bowl-shaped trithiasumanene in its inner void, forming the first ternary singlenanohoop complex. ${ }^{24}$ CPP-derived frameworks that feature two or more nanoring cycles are promising candidates for forming 1:n ternary complexes via the interaction of the host with $n$ guest molecules. ${ }^{6,8}$ In contrast with the singlenanohoop systems, multi-nanohoop systems can enable a stepwise complexation $^{8 c, d}$ or a complexation with different guest molecules, a feature of interest in porous or sensor materials design. ${ }^{6 \mathrm{~d}}$ To date, only two instances of the $1: n$ host-guest complex, namely, 1:2, have been reported, although the solid-state structures of these ternary complexes have not yet been validated by means of SC-XRD. ${ }^{8 c, d}$ To deepen our understanding of the $1: n$ complexes, which is impeded by the challenges associated with the synthesis of the host architectures, CPP-derived multi-nanohoops with improved binding abilities need to be devised.

Received: September 1, 2021

Published: September 24, 2021 
We recently reported a peropyrene-bridged double-nanohoop architecture (CPP-PP, Figure 1) constructed through a
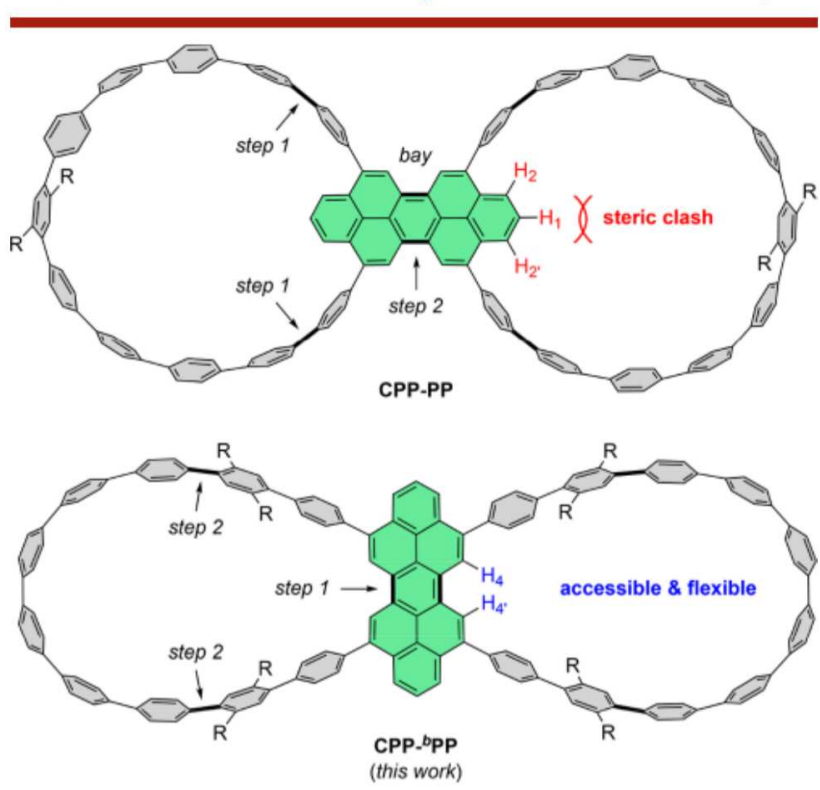

step 1: cross-coupling step 2: radical dimerization

Figure 1. Structures of peropyrene-bridged double nanohoops CPPPP $\left(\mathrm{R}=\mathrm{OC}_{3} \mathrm{H}_{7}\right)$ and $\mathbf{C P P}{ }_{-}^{b} \mathbf{P P}\left(\mathrm{R}=\mathrm{C}_{6} \mathrm{H}_{13}\right)$.

radical dimerization of a preassembled CPP loop bearing one phenalenyl unit. ${ }^{25}$ The fully $\pi$-conjugated hydrocarbon framework of CPP-PP was unambiguously validated by SC-XRD, which revealed two large circle-shaped cavities. No evidence of binding fullerenes or small polyaromatics, however, was observed, indicating that these cavities are not an ideal fit. It appeared to us that the hydrogen atoms at the two termini of the peropyrene segment $\left(\mathrm{H}_{1}, \mathrm{H}_{2}\right.$, and $\left.\mathrm{H}_{2^{\prime}}\right)$, which point inward the cavities, might cause severe steric perturbations. To eliminate such steric effect, we designed and synthesized a new, structurally modified double-nanohoop framework, CPP- ${ }^{b}$ PP (Figure 1), where the bay-regions of the central peropyrene segment are embedded within the nanoring cycles. In this manner, the cavities have an oval shape and are relieved of significant spatial obstructions from the hydrogen atoms at the bay-regions $\left(\mathrm{H}_{4}\right.$ and $\left.\mathrm{H}_{4^{\prime}}\right)$, which point inward, to activate the host functions of CPP- ${ }^{b}$ PP. During our investigations of the binding ability of this new double nanohoop, we identified and herein describe its unusual behavior in the solid state: (1) In contrast with the typically observed herringbone packing of CPPs and their analogs, $\mathbf{C P P}-{ }^{b} \mathbf{P P}$ displays a lamellar packing mode, (2) the shape of the cavities fluctuates depending on the crystallization conditions, and (3) only the 1:1 and not the 1:2 complex with $\mathrm{C}_{60}$ was observed. Intrigued by these solid-state features, we performed preliminary studies to explore the potential of $\mathbf{C P P}-{ }^{b} \mathbf{P P}$ as a solid material.

Our synthetic strategy toward $\mathbf{C P P}-{ }^{b} \mathbf{P P}$ is based on radical dimerization and Suzuki-Miyaura macrocyclization as two pivotal steps (Scheme 1). In contrast with the synthesis we employed for CPP-PP, ${ }^{25}$ the central peropyrene bridge was constructed prior to the formation of the nanoring cycles (Figure 1). 4-Iodophenyl-substituted dihydrophenalenone 4 underwent a Suzuki-Miyaura coupling to afford 3 in $60 \%$ yield, which was subjected to the reduction and dehydration to
Scheme 1. Synthesis of CPP- ${ }^{b} \mathrm{PP}\left(\mathrm{R}=\mathrm{C}_{6} \mathrm{H}_{13}\right)^{a}$
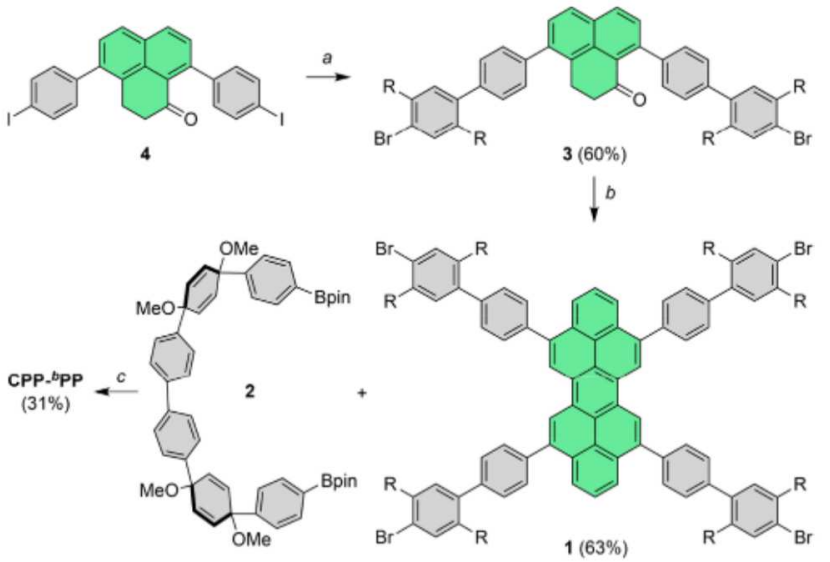

${ }^{a}$ Reaction conditions: (a) 4-bromo-2,5-dihexylphenylboronic acid, $\mathrm{Pd}\left(\mathrm{PPh}_{3}\right)_{4}, \mathrm{NaOH}(2 \mathrm{M})$, 1,4-dioxane, $80^{\circ} \mathrm{C}$; (b) (i) $\mathrm{NaBH}_{4}, \mathrm{DCM} /$ EtOH, rt, (ii) p-toluenesulfonic acid monohydrate, toluene, $90{ }^{\circ} \mathrm{C}$, (iii) $p$-chloranil, DCM/toluene, rt; (c) (i) SPhos Pd G3, $\mathrm{K}_{3} \mathrm{PO}_{4}(2$ $\mathrm{M})$, 1,4-dioxane, $80{ }^{\circ} \mathrm{C}$, (ii) sodium naphthalenide, THF, $-78{ }^{\circ} \mathrm{C}$.

afford the $1 H$-phenalene intermediate. Taking advantage of the "decomposition" pathway of phenalenyl to peropyrene, ${ }^{26}$ we treated the $1 H$-phenalene precursor with an excess of $p$ chloranil at room temperature to afford peropyrene building block 1 in a total isolated yield of $63 \%$. The construction of the cyclic scaffolds is an intractable concern in CPP chemistry. ${ }^{19}$ After screening several corner units, we found U-shaped linker $\mathbf{2}$ to be ideal to unite with $\mathbf{1}$ and afford $\mathbf{C P P}_{-}{ }^{b} \mathbf{P P}$ in $31 \%$ yield upon reductive aromatization. The hydrocarbon $\pi$-framework of CPP- ${ }^{b} \mathbf{P P}$ was unambiguously confirmed by SC-XRD (Figure 2). The concise synthesis allowed the preparation of CPP ${ }_{-}^{b} \mathbf{P P}$ on a $50 \mathrm{mg}$ scale. Benefiting from eight hexyl chains on the CPP backbone, CPP- ${ }^{b} \mathbf{P P}$ exhibits moderate solubility in common organic solvents, such as $\mathrm{CHCl}_{3}$ and toluene, which enables the solution-processed fabrication of thin films.

The X-ray diffraction (XRD) analysis of single crystals of CPP. ${ }^{b} \mathbf{P P}$, obtained by the slow vapor diffusion of acetonitrile into a $\mathrm{CHCl}_{3}$ solution at room temperature, unequivocally confirmed the structure of $\mathbf{C P P}-{ }^{b} \mathbf{P P}$ with a $C_{2}$ symmetry, where two CPP loops are tethered through a rigid peropyrene bridge to constitute a CPP-based double-nanohoop framework comprising $146 \mathrm{sp}^{2}$ carbon atoms. The different connection mode of CPP loops in CPP- ${ }^{b}$ PP compared with CPP-PP leads to dramatic changes in the dihedral angles and void shapes. The dihedral angles at the four linkages between the CPP loops and the peropyrene bridge of $\mathrm{CPP}^{-}{ }^{b} \mathrm{PP}$ are 66, 61, 66, and $61^{\circ}$ (Figure 2a), significantly smaller than those of CPPPP $\left(80^{\circ}\right.$ on average), indicating a stronger $\pi$-communication between the CPP loops and the central peropyrene segment in CPP- ${ }^{b}$ PP. This is in agreement with the red shift in the UVvis absorption spectrum of $\mathbf{C P P}-{ }^{b} \mathbf{P P}$ compared with that of CPP-PP (Figure S10). The CPP biphenylene units of CPP- ${ }^{b}$ PP display an average dihedral angle of $41^{\circ}$, greater than that of CPP-PP ( $29^{\circ}$ on average), possibly owing to the discrepancy in the void shape of the two double nanohoops. Unlike CPP-PP, which possesses two circle-shaped cavities, CPP. ${ }^{b}$ PP has two oval-shaped cavities with a long and short axis of 1.76 and $1.17 \mathrm{~nm}$, respectively. ${ }^{27}$ The overall length of the $\pi$-framework reaches $4.17 \mathrm{~nm}$. Remarkably, the solid-state structure obtained from a toluene solution exhibits two shorter 
a) $\mathrm{CHCl}_{3}$ - narrower \& longer cavity

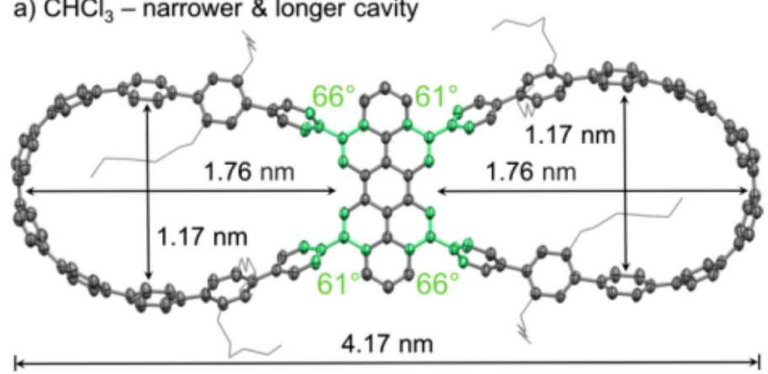

b) Toluene - wider \& shorter cavity

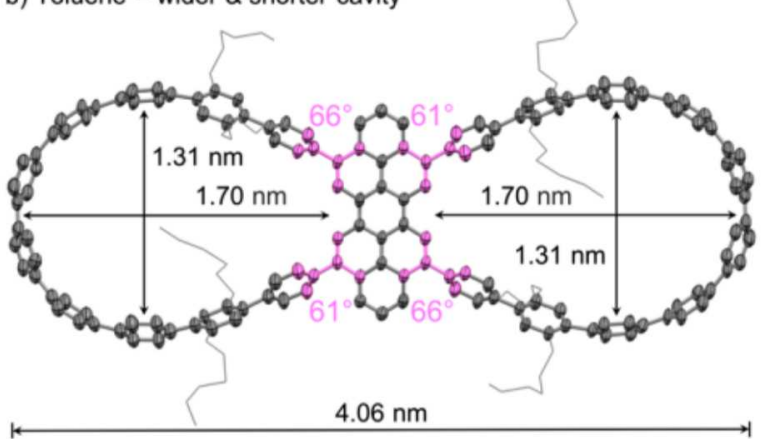

c) Toluene - encapsulation of $\mathrm{C}_{60}$

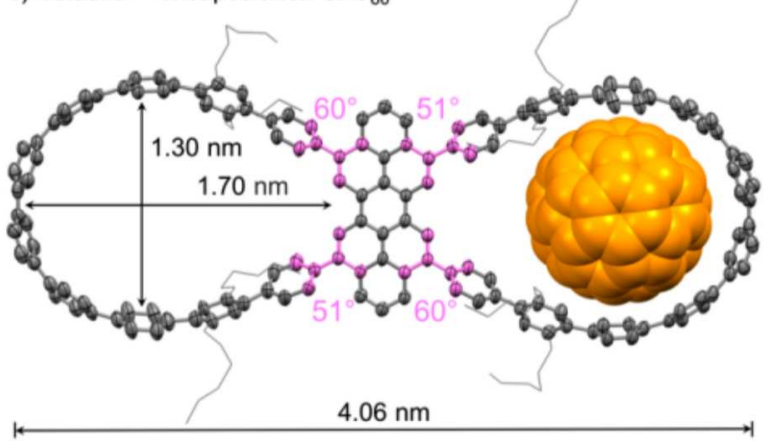

Figure 2. Solid-state structures of (a) $\mathbf{C P P}^{b}{ }^{b} \mathbf{P P}$ obtained from $\mathrm{CHCl}_{3}$, (b) $\mathbf{C P P}_{-}{ }^{b} \mathbf{P P}$ obtained from toluene, and (c) the $1: 1$ CPP- $^{b} \mathbf{P P} \mathrm{C}_{60}$ complex. Thermal ellipsoids are shown at the $20 \%$ probability level. Disordered solvent molecules are omitted for clarity.

but wider cavities with a long and short axis of 1.70 and 1.31 $\mathrm{nm}$, respectively (Figure $2 \mathrm{~b}$ ). The varied cavity size in the two solid-state structures indicates the flexible nature of the CPP loop ${ }^{28}$ and is presumably the result of the crystal packing forces. On the basis of distortion analysis (Figure S8), the phenylene rings opposite the peropyrene segment are the most strained in both cases. Given the suitable size of the cavities and the alleviated steric hindrance from the hydrogen atoms of the central peropyrene segment, $\mathbf{C P P}_{-}{ }^{b} \mathbf{P P}$ is a potential host toward $\mathrm{C}_{60}$ or $\mathrm{C}_{70}{ }^{29}$ However, no binding interaction between CPP- ${ }^{b}$ PP and $\mathrm{C}_{60} / \mathrm{C}_{70}$ was detected in solution by means of UV-vis absorption (Figure S15), fluorescence, or NMR spectroscopy, possibly due to the fact that the cavityreorganization energy counteracts the host-guest complexation energy. Nevertheless, the binding behavior was clearly observed in the solid state. Slow diffusion of acetonitrile into a toluene solution of $\mathbf{C P P}-{ }^{b} \mathbf{P P}$ and $\mathrm{C}_{60}$ at room temperature afforded single crystals of a complex. Surprisingly, a 1:1 CPP- ${ }^{b} \mathbf{P P} \supset \mathrm{C}_{60}$ complex, instead of a $1: 2$ complex, was revealed (Figure 2c). The $\mathrm{C}_{60}$ molecule resides in the center of one of the two cavities of $\mathbf{C P P}-{ }^{b} \mathbf{P P}$, leading to a strong concaveconvex $\pi-\pi$ interaction with the shortest intermolecular $\mathrm{C}-\mathrm{C}$ distance of $2.86 \AA$. In addition, an obvious quenching effect of photoluminescence was found in the spin-coated thin film of a mixture of CPP- ${ }^{b} \mathbf{P P}$ and $\mathrm{C}_{60}$ (Figure S16), indicating an interaction between the two components in the solid state.

The solid-state packing structure is one of the crucial parameters that determines charge-transport properties of organic semiconductors. ${ }^{30} \mathrm{~A}$ herringbone packing structure, typical for most CPPs, ${ }^{3}$ was observed for CPP-PP (Figure 3a).

a) CPP-PP - crystallization from $\mathrm{CHCl}_{3}$

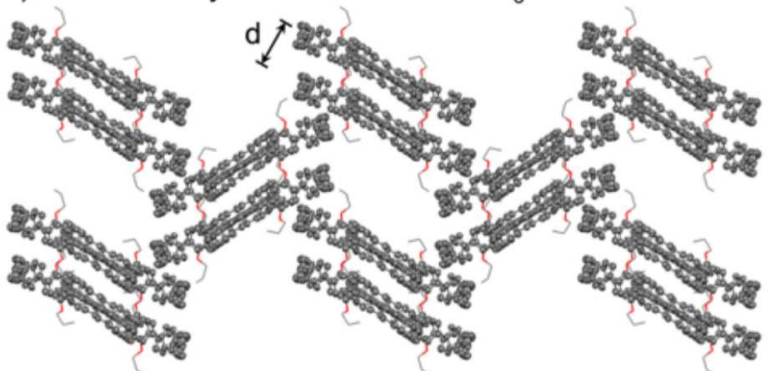

b) CPP_-bPP - crystallization from $\mathrm{CHCl}_{3}$

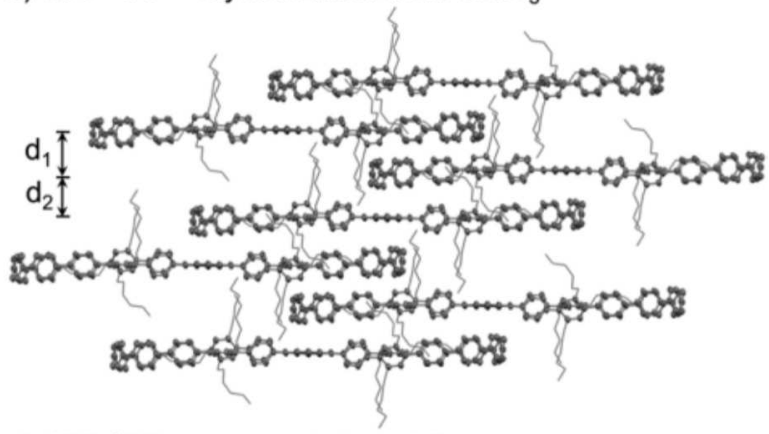

c) CPP_. ${ }^{\text {PPP }}$ - encapsulation of $\mathrm{C}_{60}$

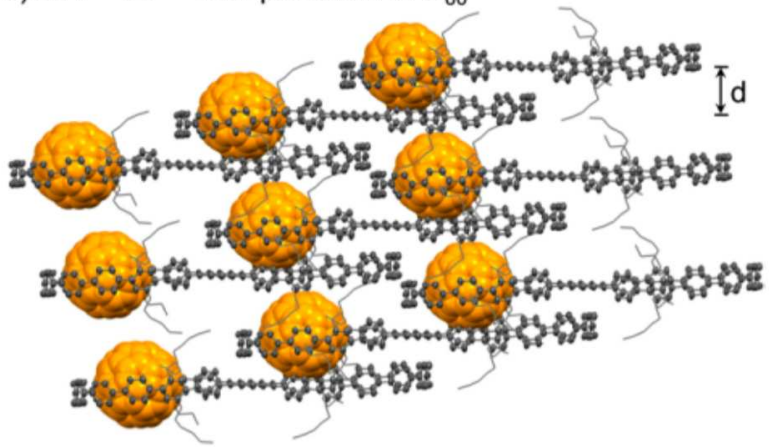

Figure 3. Packing in the solid-state structure of (a) CPP-PP, $d=$ $4.995 \AA$, (b) CPP- ${ }^{b} \mathbf{P P}$ obtained from $\mathrm{CHCl}_{3}, d_{1}=5.339 \AA, d_{2}=3.928$ $\AA$, and (c) the $1: 1 \mathrm{CPP}^{b}{ }^{b} \mathrm{PPC}_{60}$ complex, $d=6.111 \AA$. Note that the distribution of $\mathrm{C}_{60}$ shown in panel $\mathrm{c}$ is only a representative example, and $\mathrm{C}_{60}$ can randomly reside in one of the two cavities, resulting in an average ratio of $1: 1$. Thermal ellipsoids are shown at the $20 \%$ probability level. Disordered solvent molecules are omitted for clarity.

Unexpectedly, CPP- ${ }^{b} \mathbf{P P}$ adopted a lamellar packing motif (Figure $3 \mathrm{~b}$ ). To the best of our knowledge, such packing mode is unprecedented for all CPPs and architectures derived from them. Layer-to-layer, the molecules of $\mathbf{C P P}{ }^{b} \mathbf{P P}$ were offset such that the CPP loops formed diagonal columns. Within one column, $\mathrm{CH} \cdots \pi$ and $\mathrm{CH} \cdots \mathrm{CH}$ contacts were found between neighboring molecules, and the interlayer distances defined by the peropyrene planes of two $\mathbf{C P P}^{-}{ }^{b} \mathbf{P P}$ molecules were 5.339 and $3.928 \AA$ in an alternating fashion (Figure $3 \mathrm{~b}$ ). A similar 
packing pattern was found for $\mathbf{C P P}-{ }^{b} \mathbf{P P}$ obtained from toluene, but here the interlayer distance was uniform (5.347 Å, Figure S5). This unique lamellar packing mode makes CPP- ${ }^{b}$ PP a potential candidate for semiconductive materials. The CPP- ${ }^{b} \mathbf{P P} \mathrm{CC}_{60}$ complex exhibited a packing structure (Figure 3c) that was almost identical to that of $\mathbf{C P P}{ }^{b} \mathbf{P P}$ obtained from toluene, except for an increased interlayer distance of $6.111 \AA$. It is plausible that such a tight lamellar packing motif is the reason for the formation of the $1: 1$ complex and not the 1:2 complex. If a $1: 2 \mathbf{C P P}_{-}{ }^{b} \mathbf{P P} \mathrm{CC}_{60}$ complex would form, significant steric repulsion would arise between the neighboring $\mathrm{C}_{60}$ molecules (shortest $\mathrm{C}-\mathrm{C}$ distance of $2.24 \AA$, Figure S7b), given that the packing and interlayer distance would stay the same.

Inspired by the unique lamellar packing motif of $\mathbf{C P P}_{-}{ }^{b} \mathbf{P P}$ and the electronic properties of CPPs and their derived structures, we measured the electrical conductivity of the single crystals of $\mathrm{CPP}^{-}{ }^{b} \mathbf{P P}$ (see the Supporting Information for details). CPP- ${ }^{b}$ PP showed a conductivity value of $5.8 \times 10^{-3} \mathrm{~S}$ $\mathrm{cm}^{-1}$, comparable to that of its structural analog CPP-PP (5.9 $\left.\times 10^{-3} \mathrm{~S} \mathrm{~cm}^{-1}\right)$ and higher than that of $\mathrm{C}_{60}\left(1.7 \times 10^{-8} \mathrm{~S}\right.$ $\left.\mathrm{cm}^{-1}\right) .{ }^{31}$ The reason why $\mathbf{C P P}{ }^{b} \mathbf{P P}$ does not display higher conductivity than CPP-PP is presumably the lack of $\pi-\pi$ interactions between the peropyrene units of the neighboring CPP- ${ }^{b} \mathbf{P P}$ molecules, where the HOMO is predominantly distributed, and the relatively large interlayer distance. Nevertheless, alteration of the crystal packing in these two regards could improve the charge-transport properties.

In summary, we synthesized a novel member of the CPPderived double-nanohoop family, $\mathbf{C P P}-{ }_{-}^{b} \mathbf{P P}$, in which the bayregions of the peropyrene bridge are incorporated within the nanoring cycles. The skeletal modification with regards to the structural analog CPP-PP gives rise to a remarkable change in the packing motif identified in the solid state, where an unprecedented lamellar packing was observed. This packing mode is in stark contrast with the herringbone motif typically observed for CPPs and CPP-derived structures. Because of the relief of steric obstruction in $\mathbf{C P P}_{-}{ }^{b} \mathbf{P P}$ compared with CPPPP, the large voids of CPP- ${ }^{b} \mathbf{P P}$ enable it to function as a molecular host toward $\mathrm{C}_{60}$ in the solid state. Interestingly, the lamellar arrangement of $\mathbf{C P P}_{-}{ }^{b} \mathbf{P P}$ molecules allows the formation of only a $1: 1 \mathbf{C P P}^{b} \mathbf{P P} \supset \mathrm{C}_{60}$ complex, which has been validated by SC-XRD. Finally, CPP- ${ }^{b} \mathbf{P P}$ performs as a semiconductive material with a conductivity value of $5.8 \times$ $10^{-3} \mathrm{~S} \mathrm{~cm} \mathrm{~cm}^{-1}$. Given the unique solid-state structure of CPP- ${ }^{b} \mathbf{P P}$, we envision that a fullerene $\mathrm{C}_{60}$ dimer, namely, $\mathrm{C}_{120}{ }^{32}$ could be an ideal guest molecule for encapsulation by CPP- ${ }^{b}$ PP to accomplish the full occupancy of its two cavities and the formation of encapsulated zigzag $\mathrm{C}_{60}$ wires. Such fullerene-based conductive supramolecular wires ${ }^{33}$ are of interest as organic semiconductors. We believe that our results will aid the crystal engineering of CPPs and CPP-based nanohoops and promote their application in semiconductive materials and host-guest chemistry.

\section{ASSOCIATED CONTENT}

\section{Supporting Information}

The Supporting Information is available free of charge at https://pubs.acs.org/doi/10.1021/acs.orglett.1c02950.

Experimental procedures, characterization data $\left({ }^{1} \mathrm{H}\right.$ and ${ }^{13} \mathrm{C}$ NMR and HRMS), X-ray analysis, photophysical and redox data, and density functional theory calculations (PDF)

\section{Accession Codes}

CCDC 2104607-2104609 contain the supplementary crystallographic data for this paper. These data can be obtained free of charge via www.ccdc.cam.ac.uk/data request/cif, or by emailing data_request@ccdc.cam.ac.uk, or by contacting The Cambridge Crystallographic Data Centre, 12 Union Road, Cambridge CB2 1EZ, UK; fax: +44 1223336033.

\section{AUTHOR INFORMATION}

\section{Corresponding Author}

Michal Jurícek - Department of Chemistry, University of Zurich, CH-8057 Zurich, Switzerland; 1 orcid.org/00000001-5595-431X; Email: michal.juricek@chem.uzh.ch

\section{Authors}

Yong Yang - Department of Chemistry, University of Zurich, CH-8057 Zurich, Switzerland

Shangxiong Huangfu - Laboratory for High Performance Ceramics, Empa, CH-8600 Dübendorf, Switzerland; Department of Physics, University of Zurich, $\mathrm{CH}-8057$ Zurich, Switzerland

Sota Sato - Department of Applied Chemistry, School of Engineering, The University of Tokyo, Tokyo 113-8656, Japan; - orcid.org/0000-0002-7395-2112

Complete contact information is available at:

https://pubs.acs.org/10.1021/acs.orglett.1c02950

Notes

The authors declare no competing financial interest.

\section{ACKNOWLEDGMENTS}

This project received funding from the European Research Council (ERC) under the European Union's Horizon 2020 research and innovation programme (Grant Agreement No. 716139) and the Swiss National Science Foundation (SNSF, PP00P2_170534, and PP00P2_198900). We are grateful to Dr. Efrain Ochoa Martinez (Adolphe Merkle Institute, Switzerland) for preparing thin films, Brian Carlsen (EPFL, Switzerland) for recording photoluminescence spectra, Dr. Jovana V. Milić (Adolphe Merkle Institute and EPFL, Switzerland) for supporting the analysis of thin films, Prof. Qian Miao and Qi Gong (The Chinese University of Hong Kong) for their help with a preliminary study of organic thinfilm transistors, and KEK Photon Factory (No. 2019G051) and SPring-8 (No. 2021A2765) for the access to the X-ray diffraction instrument.

\section{REFERENCES}

(1) Selected reviews of CPPs: (a) Omachi, H.; Segawa, Y.; Itami, K. Synthesis of Cycloparaphenylenes and Related Carbon Nanorings: A Step toward the Controlled Synthesis of Carbon Nanotubes. Acc. Chem. Res. 2012, 45, 1378-1389. (b) Lewis, S. E. Cycloparaphenylenes and Related Nanohoops. Chem. Soc. Rev. 2015, 44, 2221-2304. (c) Golder, M. R; Jasti, R. Syntheses of the Smallest Carbon Nanohoops and the Emergence of Unique Physical Phenomena. Acc. Chem. Res. 2015, 48, 557-566. (d) Darzi, E. R; Jasti, R. The dynamic, Size-dependent Properties of [5]-[12]Cycloparaphenylenes. Chem. Soc. Rev. 2015, 44, 6401-6410. (e) Wu, D.; Cheng, W.; Ban, X.; Xia, J. Cycloparaphenylenes (CPPs): An 
Overview of Synthesis, Properties, and Potential Applications. Asian J. Org. Chem. 2018, 7, 2161-2181.

(2) (a) Omachi, H.; Nakayama, T.; Takahashi, E.; Segawa, Y.; Itami, K. Initiation of Carbon Nanotube Growth by Well-defined Carbon Nanorings. Nat. Chem. 2013, 5, 572-576. (b) Segawa, Y.; Yagi, A.; Matsui, K.; Itami, K. Design and Synthesis of Carbon Nanotube Segments. Angew. Chem., Int. Ed. 2016, 55, 5136-5158.

(3) (a) Xu, Y.; von Delius, M. The Supramolecular Chemistry of Strained Carbon Nanohoops. Angew. Chem., Int. Ed. 2020, 59, 559573. (b) Lu, D.; Huang, Q.; Wang, S.; Wang, J.; Huang, P.; Du, P. The Supramolecular Chemistry of Cycloparaphenylenes and Their Analogs. Front. Chem. 2019, 7, 668.

(4) Leonhardt, E. J.; Jasti, R. Emerging Applications of Carbon Nanohoops. Nat. Rev. Chem. 2019, 3, 672-686.

(5) Jasti, R.; Bhattacharjee, J.; Neaton, J. B.; Bertozzi, C. R. Synthesis, Characterization, and Theory of [9]-, [12]-, and [18]Cycloparaphenylene: Carbon Nanohoop Structures. J. Am. Chem. Soc. 2008, 130, 17646-17647.

(6) (a) Huang, Z.-A.; Chen, C.; Yang, X.-D.; Fan, X.-B.; Zhou, W.; Tung, C.-H.; Wu, L.-Z.; Cong, H. Synthesis of OligoparaphenyleneDerived Nanohoops Employing an Anthracene PhotodimerizationCycloreversion Strategy. J. Am. Chem. Soc. 2016, 138, 11144-11147. (b) Xu, W.; Yang, X.-D.; Fan, X.-B.; Wang, X.; Tung, C.-H.; Wu, L.Z.; Cong, H. Synthesis and Characterization of a PentiptyceneDerived Dual Oligoparaphenylene Nanohoop. Angew. Chem., Int. Ed. 2019, 58, 3943-3947. (c) Senthilkumar, K; Kondratowicz, M.; Lis, T.; Chmielewski, P. J.; Cybińska, J.; Zafra, J. L.; Casado, J.; Vives, T.; Crassous, J.; Favereau, L.; Stępień, M. Lemniscular [16]Cycloparaphenylene: A Radially Conjugated Figure-Eight Aromatic Molecule. J. Am. Chem. Soc. 2019, 141, 7421-7427. (d) Schaub, T. A.; Prantl, E. A.; Kohn, J.; Bursch, M.; Marshall, C. R.; Leonhardt, E. J.; Lovell, T. C.; Zakharov, L. N.; Brozek, C. K.; Waldvogel, S. R.; Grimme, S.; Jasti, R. Exploration of the Solid-State Sorption Properties of Shape-Persistent Macrocyclic Nanocarbons as Bulk Materials and Small Aggregates. J. Am. Chem. Soc. 2020, 142, 87638775 .

(7) (a) Sun, Z.; Ikemoto, K.; Fukunaga, T. M.; Koretsune, T.; Arita, R.; Sato, S.; Isobe, H. Finite Phenine Nanotubes with Periodic Vacancy Defects. Science 2019, 363, 151-155. (b) Ikemoto, K.; Yang, S.; Naito, H.; Kotani, M.; Sato, S.; Isobe, H. A Nitrogen-doped Nanotube Molecule with Atom Vacancy Defects. Nat. Commun. 2020, $11,1807$.

(8) (a) Xia, J.; Golder, M. R.; Foster, M. E.; Wong, B. M.; Jasti, R. Synthesis, Characterization, and Computational Studies of Cycloparaphenylene Dimers. J. Am. Chem. Soc. 2012, 134, 19709-19715. (b) Ishii, Y.; Matsuura, S.; Segawa, Y.; Itami, K. Synthesis and Dimerization of Chloro[10]cycloparaphenylene: A Directly Connected Cycloparaphenylene Dimer. Org. Lett. 2014, 16, 2174-2176. (c) Li, K.; Xu, Z.; Deng, H.; Zhou, Z.; Dang, Y.; Sun, Z. Dimeric Cycloparaphenylenes with a Rigid Aromatic Linker. Angew. Chem., Int. Ed. 2021, 60, 7649-7653. (d) Zhang, X.; Shi, H.; Zhuang, G.; Wang, S.; Wang, J.; Yang, S.; Shao, X.; Du, P. A Highly Strained AllPhenylene Conjoined Bismacrocycle. Angew. Chem., Int. Ed. 2021, 60, 17368-17372.

(9) Li, P.; Zakharov, L. N.; Jasti, R. A Molecular Propeller with Three Nanohoop Blades: Synthesis, Characterization, and Solid-State Packing. Angew. Chem., Int. Ed. 2017, 56, 5237-5241.

(10) (a) Matsui, K.; Segawa, Y.; Namikawa, T.; Kamada, K.; Itami, K. Synthesis and Properties of All-Benzene Carbon Nanocages: A Junction Unit of Branched Carbon Nanotubes. Chem. Sci. 2013, 4, 84-88. (b) Matsui, K.; Segawa, Y.; Itami, K. All-Benzene Carbon Nanocages: Size-Selective Synthesis, Photophysical Properties, and Crystal Structure. J. Am. Chem. Soc. 2014, 136, 16452-16458. (c) Kayahara, E.; Iwamoto, T.; Takaya, H.; Suzuki, T.; Fujitsuka, M.; Majima, T.; Yasuda, N.; Matsuyama, N.; Seki, S.; Yamago, S. Synthesis and Physical Properties of a Ball-like Three-Dimensional $\pi$ Conjugated Molecule. Nat. Commun. 2013, 4, 2694. (d) Cui, S.; Zhuang, G.; Lu, D.; Huang, Q.; Jia, H.; Wang, Y.; Yang, S.; Du, P. A Three-Dimensional Capsule-like Carbon Nanocage as a Segment
Model of Capped Zigzag [12,0] Carbon Nanotubes: Synthesis, Characterization, and Complexation with $\mathrm{C}_{70}$. Angew. Chem., Int. Ed. 2018, 57, 9330-9335.

(11) (a) Zhang, W.; Abdulkarim, A.; Golling, F. E.; Räder, H. J.; Müllen, K. Cycloparaphenylenes and Their Catenanes: Complex Macrocycles Unveiled by Ion Mobility Mass Spectrometry. Angew. Chem., Int. Ed. 2017, 56, 2645-2648. (b) Fan, Y.-Y.; Chen, D.; Huang, Z.-A.; Zhu, J.; Tung, C.-H.; Wu, L.-Z.; Cong, H. An Isolable Catenane Consisting of Two Möbius Conjugated Nanohoops. Nat. Commun. 2018, 9, 3037. (c) Segawa, Y.; Kuwayama, M.; Hijikata, Y.; Fushimi, M.; Nishihara, T.; Pirillo, J.; Shirasaki, J.; Kubota, N.; Itami, K. Topological Molecular Nanocarbons: All-Benzene Catenane and Trefoil Knot. Science 2019, 365, 272-276. (d) Segawa, Y.; Kuwayama, M.; Itami, K. Synthesis and Structure of [9]Cycloparaphenylene Catenane: An All-Benzene Catenane Consisting of Small Rings. Org. Lett. 2020, 22, 1067-1070.

(12) Segawa, Y.; Miyamoto, S.; Omachi, H.; Matsuura, S.; Šenel, P.; Sasamori, T.; Tokitoh, N.; Itami, K. Concise Synthesis and Crystal Structure of [12]Cycloparaphenylene. Angew. Chem., Int. Ed. 2011, $50,3244-3248$.

(13) Xia, J.; Jasti, R. Synthesis, Characterization, and Crystal Structure of [6] Cycloparaphenylene. Angew. Chem., Int. Ed. 2012, 51, 2474-2476.

(14) Fukushima, T.; Sakamoto, H.; Tanaka, K.; Hijikata, Y.; Irle, S.; Itami, K. Polymorphism of [6]Cycloparaphenylene for Packing Structure-dependent Host-Guest Interaction. Chem. Lett. 2017, 46, 855-857.

(15) (a) Hashimoto, S.; Kayahara, E.; Mizuhata, Y.; Tokitoh, N.; Takeuchi, K.; Ozawa, F.; Yamago, S. Synthesis and Physical Properties of Polyfluorinated Cycloparaphenylenes. Org. Lett. 2018, 20, 59735976. (b) Leonhardt, E. J.; Van Raden, J. M.; Miller, D.; Zakharov, L. N.; Alemán, B.; Jasti, R. A Bottom-Up Approach to SolutionProcessed, Atomically Precise Graphitic Cylinders on Graphite. Nano Lett. 2018, 18, 7991-7997. (c) Van Raden, J. M.; Leonhardt, E. J.; Zakharov, L. N.; Pérez-Guardiola, A.; Pérez-Jiménez, A. J.; Marshall, C. R.; Brozek, C. K.; Sancho-García, J. C.; Jasti, R. Precision Nanotube Mimics via Self-Assembly of Programmed Carbon Nanohoops. J. Org. Chem. 2020, 85, 129-141.

(16) (a) Miyauchi, Y.; Johmoto, K.; Yasuda, N.; Uekusa, H.; Fujii, S.; Kiguchi, M.; Ito, H.; Itami, K.; Tanaka, K. Concise Synthesis and Facile Nanotube Assembly of a Symmetrically Multifunctionalized Cycloparaphenylene. Chem. - Eur. J. 2015, 21, 18900-18904. (b) Hayase, N.; Miyauchi, Y.; Aida, Y.; Sugiyama, H.; Uekusa, H.; Shibata, Y.; Tanaka, K. Synthesis of [8]Cycloparaphenyleneoctacarboxylates via Rh-Catalyzed Stepwise Cross-Alkyne Cyclotrimerization. Org. Lett. 2017, 19, 2993-2996.

(17) (a) Ito, H.; Mitamura, Y.; Segawa, Y.; Itami, K. ThiopheneBased, Radial $\pi$-Conjugation: Synthesis, Structure, and Photophysical Properties of Cyclo-1,4-phenylene-2',5'-thienylenes. Angew. Chem., Int. Ed. 2015, 54, 159-163. (b) Darzi, E. R.; Hirst, E. S.; Weber, C. D.; Zakharov, L. N.; Lonergan, M. C.; Jasti, R. Synthesis, Properties, and Design Principles of Donor-Acceptor Nanohoops. ACS Cent. Sci. 2015, 1, 335-342.

(18) Zhou, Z.; Wei, Z.; Schaub, T. A.; Jasti, R.; Petrukhina, M. A. Structural Deformation and Host-Guest Properties of Doublyreduced Cycloparaphenylenes, $[n] \mathrm{CPPs}^{2-}(n=6,8,10$, and 12). Chem. Sci. 2020, 11, 9395-9401.

(19) Mirzaei, S.; Castro, E.; Hernández Sánchez, R. Conjugated Molecular Nanotubes. Chem. - Eur. J. 2021, 27, 8642-8655.

(20) (a) Sakamoto, H.; Fujimori, T.; Li, X.; Kaneko, K.; Kan, K.; Ozaki, N.; Hijikata, Y.; Irle, S.; Itami, K. Cycloparaphenylene as a Molecular Porous Carbon Solid with Uniform Pores Exhibiting Adsorption-induced Softness. Chem. Sci. 2016, 7, 4204-4210. (b) Ozaki, N.; Sakamoto, H.; Nishihara, T.; Fujimori, T.; Hijikata, Y.; Kimura, R.; Irle, S.; Itami, K. Electrically Activated Conductivity and White Light Emission of a Hydrocarbon Nanoring-Iodine Assembly. Angew. Chem., Int. Ed. 2017, 56, 11196-11202. (c) Kayahara, E.; Sun, L.; Onishi, H.; Suzuki, K.; Fukushima, T.; Sawada, A.; Kaji, H.; Yamago, S. Gram-Scale Syntheses and 
Conductivities of [10]Cycloparaphenylene and Its Tetraalkoxy Derivatives. J. Am. Chem. Soc. 2017, 139, 18480-18483.

(21) Iwamoto, T.; Watanabe, Y.; Sadahiro, T.; Haino, T.; Yamago, S. Size-Selective Encapsulation of $\mathrm{C}_{60}$ by [10]Cycloparaphenylene: Formation of the Shortest Fullerene-Peapod. Angew. Chem., Int. Ed. 2011, 50, 8342-8344.

(22) Xia, J.; Bacon, J. W.; Jasti, R. Gram-Scale Synthesis and Crystal Structures of [8]- and [10]CPP, and the Solid-State Structure of $\mathrm{C}_{60} @[10]$ CPP. Chem. Sci. 2012, 3, 3018-3021.

(23) (a) Hashimoto, S.; Iwamoto, T.; Kurachi, D.; Kayahara, E.; Yamago, S. Shortest Double-Walled Carbon Nanotubes Composed of Cycloparaphenylenes. ChemPlusChem 2017, 82, 1015-1020.

(b) Zhao, C.; Liu, F.; Feng, L.; Nie, M.; Lu, Y.; Zhang, J.; Wang, C.; Wang, T. Construction of a Double-walled Carbon Nanoring. Nanoscale 2021, 13, 4880-4886.

(24) Qiu, Z.-L.; Tang, C.; Wang, X.-R.; Ju, Y.-Y.; Chu, K.-S.; Deng, Z.-Y.; Hou, H.; Liu, Y.-M.; Tan, Y.-Z. Tetra-benzothiadiazole-based [12]Cycloparaphenylene with Bright Emission and Its Supramolecular Assembly. Angew. Chem., Int. Ed. 2020, 59, 20868-20872.

(25) Yang, Y.; Blacque, O.; Sato, S.; Juríček, M. Cycloparaphenylene-Phenalenyl Radical and Its Dimeric Double Nanohoop. Angew. Chem., Int. Ed. 2021, 60, 13529-13535.

(26) Uchida, K.; Ito, S.; Nakano, M.; Abe, M.; Kubo, T. Biphenalenylidene: Isolation and Characterization of the Reactive Intermediate on the Decomposition Pathway of Phenalenyl Radical. J. Am. Chem. Soc. 2016, 138, 2399-2410.

(27) In Figure 2, the long axes are defined as the average distance between the hydrogen atoms in the bay-region of the central peropyrene segment $\left(\mathrm{H}_{4}\right.$ and $\left.\mathrm{H}_{4^{\prime}}\right)$ and the opposing quaternary carbon atoms. The short axes are defined as the distance between the mean planes of the two opposing phenylene rings, as indicated by the double-head arrow.

(28) Frydrych, R.; Lis, T.; Bury, W.; Cybińska, J.; Stępień, M. Feeding a Molecular Squid: A Pliable Nanocarbon Receptor for Electron-Poor Aromatics. J. Am. Chem. Soc. 2020, 142, 15604-15613.

(29) Iwamoto, T.; Watanabe, Y.; Takaya, H.; Haino, T.; Yasuda, N.; Yamago, S. Size- and Orientation-Selective Encapsulation of $\mathrm{C}_{70}$ by Cycloparaphenylenes. Chem. - Eur. J. 2013, 19, 14061-14068.

(30) Wang, C.; Dong, H.; Hu, W.; Liu, Y.; Zhu, D. Semiconducting $\pi$-Conjugated Systems in Field-Effect Transistors: A Material Odyssey of Organic Electronics. Chem. Rev. 2012, 112, 2208-2267.

(31) Wen, C.; Li, J.; Kitazawa, K.; Aida, T.; Honma, I.; Komiyama, H.; Yamada, K. Electrical Conductivity of a Pure $\mathrm{C}_{60}$ Single Crystal. Appl. Phys. Lett. 1992, 61, 2162-2163.

(32) Wang, G.-W.; Komatsu, K.; Murata, Y.; Shiro, M. Synthesis and X-Ray Structure of Dumb-bell-shaped $C_{120}$. Nature 1997, 387, 583586.

(33) Barnes, J. C.; Dale, E. J.; Prokofjevs, A.; Narayanan, A.; GibbsHall, I. C.; Juríček, M.; Stern, C. L.; Sarjeant, A. A.; Botros, Y. Y.; Stupp, S. I.; Stoddart, J. F. Semiconducting Single Crystals Comprising Segregated Arrays of Complexes of $\mathrm{C}_{60}$. J. Am. Chem. Soc. 2015, 137, 2392-2399. 